\title{
O DEGELO NO ÁRTICO E A NOVA FRENTE GEOPOLÍTICA PARA A RÚSSIA'
}

\author{
MELTING IN THE ARCTIC AND A NEW GEOPOLITICAL FRONT FOR RUSSIA
}

DOI: $10.5380 / \mathrm{cg} . v 10 i 1.76150$

Pedro Henrique Iranço Silva²

Naiane Inez Cossul3

\begin{abstract}
Resumo
Com o arrefecimento da Guerra Fria, o Ártico passou de um palco de tensões para uma zona de cooperação. Porém o degelo que ocorre em virtude das mudanças climáticas traz implicações para o desenvolvimento geopolítico da região, devido às grandes camadas de petróleo e gás natural que se tornam acessíveis, principalmente à Rússia. A partir desse contexto, o presente artigo analisa como o degelo do Ártico vem influenciando as dinâmicas geopolíticas do Estado russo na região. Para isso, o artigo está dividido em quatro seções. A primeira apresenta os aspectos históricos e geopolíticos russos no Ártico no século XX. A segunda seção mostra o impacto das mudanças climáticas no Ártico. A terceira seção aborda o novo cenário russo em virtude das mudanças climáticas, analisando como a corrida pelos recursos do Mar Ártico vem aumentando a militarização da região. Dentro desse contexto, parte-se do Dilema de Segurança de Herz (1950) e o Balancing de Waltz (1979) para explicar o desenvolvimento securitário da região, de modo que a quarta seção aborda como o degelo do Ártico traz novas estratégias para países ocidentais e asiáticos, buscando colocar em xeque a influência geopolítica russa. O artigo conclui que há uma correlação direta entre a exposição dos recursos energéticos pelo degelo e o aumento da militarização, tanto pelos russos como pelos diversos atores, podendo escalar para um nível de tensão igual ou maior que o da Guerra Fria.
\end{abstract}

Palavras Chave: Ártico; Geopolítica; Rússia; Mudanças Climáticas; Segurança Internacional.

\begin{abstract}
With the end of the Cold War, the Arctic has gone from a stage of tensions to a cooperation zone. However, the thaw happening due to climate change brings implications to the region's geopolitical development, due to large layers of hydrocarbons that become available, mainly in Russia. On this basis, the present article analyses how the Arctic thaw is influencing the Russian's geopolitical dynamics in the region. For that, the article is divided into four sections. The first section presents the Russian's historical and geopolitical aspects in the Arctic in the 20th century. The second section addresses the climate changes and their effects on the Arctic. The third section addresses the new scenario put to Russia due to the climate change, analyzing how the race for the resources is increasing the militarization of the region. Within that context it is used the Security

\footnotetext{
${ }^{1}$ Este artigo está licenciado sob a Licença Creative Commons Attribution (CC BY 4.0), sendo permitido o compartilhamento com reconhecimento da autoria e publicação inicial nesta revista.

${ }^{2}$ Graduando do $8^{\circ}$ semestre do Curso de Relações Internacionais pelo Centro Universitário Ritter dos Reis (UniRitter). Pesquisador do Laboratório de Estudos em Defesa e Segurança (LEDS) da mesma instituição. Email: pedroiranco@gmail.com. ORCID: https://orcid.org/0000-0003-1443-0397.

3 Coordenadora e professora do curso de graduação em Relações Internacionais no Centro Universitário Ritter dos Reis (UniRitter). Doutora em Estudos Estratégicos Internacionais pela Universidade Federal do Rio Grande do Sul (UFRGS). E-mail: naianecossul@hotmail.com. ORCID: https://orcid.org/oooo-0001-90069607.
} 
Dilemma from Herz (1950) and the Balancing of Waltz (1979) to explain the region's security development. The fourth section addresses how the Arctic's thaw brings new strategies for western and Asian countries, seeking to put in check the Russian geopolitical influence. The article concluded that there is a direct correlation between the exposure of energy resources by thawing and the increase in militarization, both by the Russians and by the various actors, which may escalate to a level of tension equal to or greater than the Cold War.

Keywords: Arctic; Geopolitics; Russia; Climate Change; International Security.

\section{INTRODUÇÃO}

Ao longo dos séculos, o Ártico apresentou-se como uma barreira à exploração e ao povoamento da humanidade na região. As baixas temperaturas impediam o largo desenvolvimento de qualquer tipo de atividade econômica, sendo, por boa parte da história humana, uma região de difícil acesso. Além desses atributos, o Ártico serviu, em grande parte para o Império Russo e União Soviética, como uma proteção ao avanço militar de outros Estados, sendo o Mar Ártico considerado uma fortaleza impenetrável (JOSEPHSON, 2014).

Em questão de um século, as mudanças climáticas mostraram-se o principal ator no Ártico. Graças a elas, vemos um cenário completamente diferente na região (THOMAN et al, 2020). Terras com difícil acesso tornaram-se mais acessíveis, possibilitando a militarização desse território e virando palco de tensões nucleares na Guerra Fria. Nos últimos anos, as camadas glaciais do Ártico têm derretido progressivamente, possibilitando acesso facilitado a novos submarinos e navios quebra-gelo russos e, com o derretimento do gelo marítimo, tornando disponível uma das maiores reservas de petróleo e gás natural do mundo.

A partir desse contexto, o presente artigo analisa como o degelo do Ártico vem influenciando dinâmicas geopolíticas do Estado russo na região. Para isso, o artigo está dividido em quatro seções. A primeira seção apresenta os principais aspectos históricos e geopolíticos russos no Ártico, tendo como espaço temporal o século XX. A segunda seção aborda os impactos das mudanças climáticas no Ártico e como isso transforma a região, apresentando novos desafios para os países com atuação no Mar Ártico. A terceira seção contextualiza o novo cenário posto à Rússia em virtude das mudanças climáticas, analisando como a corrida pelos recursos do Mar Ártico aumenta a militarização da região e sua relação com outros Estados. Dentro desse contexto, parte-se do Dilema de Segurança (HERZ, 1950) e o Balancing (WALTZ, 1979; WALT, 1985) para explicar o aumento da tensão e a formação de cooperações político e militares na região. A quarta seção aborda como o degelo do Ártico traz novas estratégias para os países membros da OTAN e a China, gerando uma nova dinâmica para a geopolítica russa.

A metodologia qualitativa de caráter explicativa usada neste artigo possibilita responder quais as consequências do degelo no Ártico para a Rússia e como as ações desse Estado na região são reações a esse fenômeno, contribuindo para a ampliação dos estudos brasileiros sobre a região. A 
hipótese entende que o degelo no Ártico catalisa o aumento das capacidades militares russas à medida que o degelo ocorre, tornando-se assim uma região cada vez mais disputada. A pesquisa foi realizada por meio de revisão bibliográfica a partir de artigos de revistas científicas, dissertações, teses e livros, bem como os documentos oficiais dos países mencionados e notícias que exemplifiquem seus objetivos na região.

O artigo conclui que o propósito russo é, portanto, garantir que o Ártico, devido às mudanças climáticas, seja a sua nova frente geopolítica, uma vez que o acesso russo aos oceanos é vulnerável. Com o degelo, os portos árticos, que ficam em águas congeladas na maior parte do ano, poderiam ser utilizados ilimitadamente, fazendo com que a Rússia deixe de depender de outras rotas marítimas (comerciais e militares) que poderiam facilmente ser bloqueadas, como é o caso do Mar Negro e do Estreito de Bósforo. Do mesmo modo, os recursos naturais presentes na região podem ser decisivos nos propósitos russos, especialmente de Putin, de modernização econômica, militar e geopolítica.

\section{O DESENVOLVIMENTO DO ÁRTICO NO SÉCULO XX}

As tentativas de “conquista” ao Ártico não são recentes. Ainda no período da União Soviética, ocorreram diversos projetos para exploração e pesquisa na região. Além disso, a própria natureza da Rússia - perpassando o Império Russo, a União Soviética e a Federação Russa - é garantir a sua segurança territorial. Nesse sentido, o objetivo russo, ainda hoje, é "tomar o controle militar sobre as zonas centrais anexadas, no sul e no oeste, e na esfera do norte do Oceano Atlântico" (DUGIN, 2015, p. 12-13). Com a securitização do Ártico, foi objetivado o uso dos recursos naturais disponíveis, especialmente minérios de ferro, essenciais para a industrialização que ocorria na Rússia de Stálin (LAURELLE, 2014). Esse projeto de expansão ocorrido na União das Repúblicas Socialistas Soviéticas (URSS) pré-Guerra Fria, contou com esforços por parte de militares, exploradores e trabalhadores soviéticos.

Em virtude disso, foi possível um extenso mapeamento do terreno e catalogação de fauna e flora, culminando na expansão do conhecimento russo na oceanografia, geografia e geologia do Ártico. A partir desses conhecimentos, foi possível a criação da Rota do Norte (Figura 1), que consiste em uma das principais rotas de navegação russa, servindo tanto aos interesses comerciais quanto militares na região. A Rota possui mais de 5 mil km, percorrendo desde Murmansk até Vladivostok, possuindo valor estratégico por conta do fluxo de recursos energéticos que são transportados lá (JOSEPHSON, 2014). 


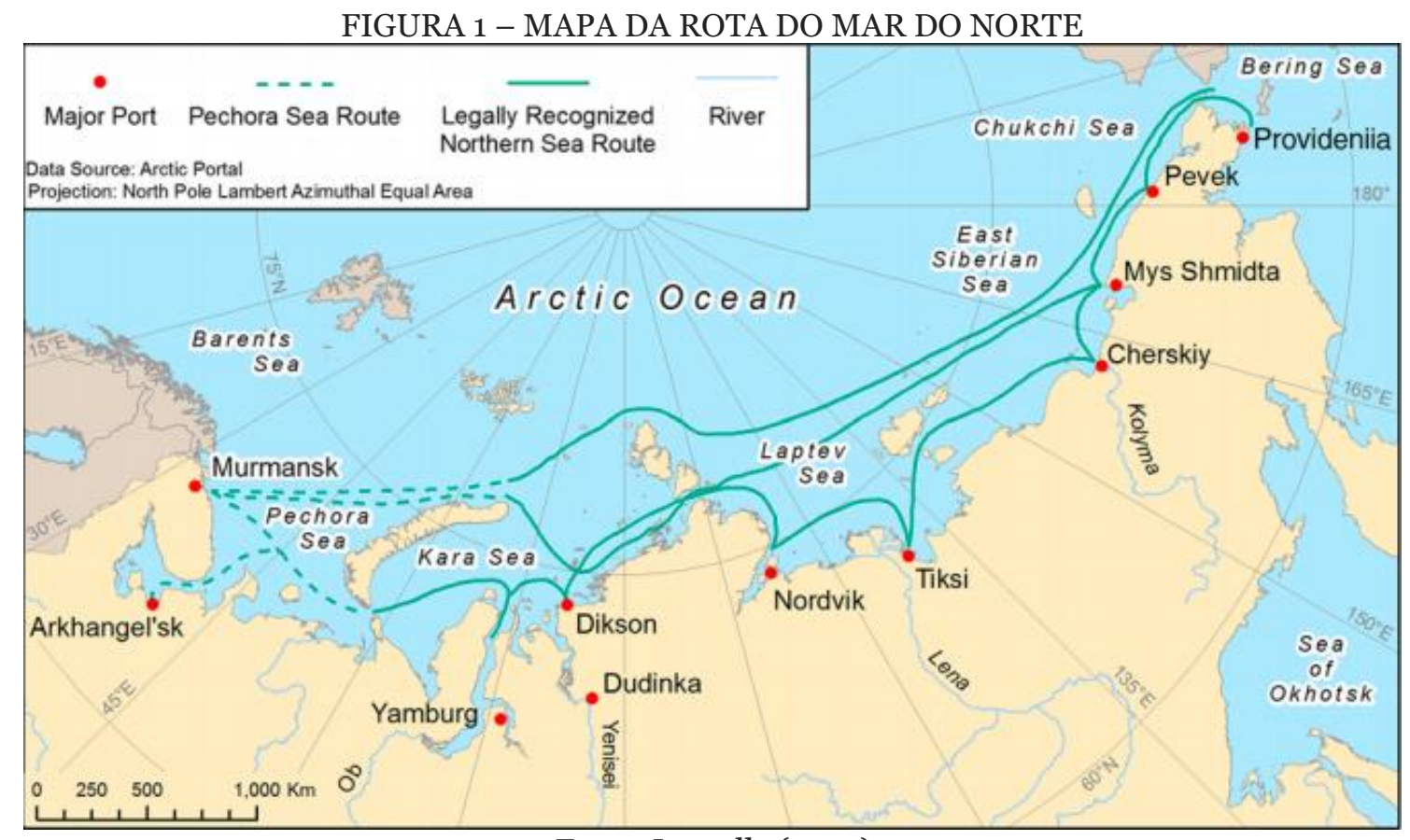

Fonte: Laurelle (2014)

Destaca-se também a Guerra Fria como importante período na região, sendo o Mar Ártico uma região com alta presença de submarinos soviéticos e estadunidenses devido à proximidade territorial entre os dois países e a capacidade de camuflagem que os ruídos do gelo ofereciam para os submarinos em sonares inimigos (GUNITSKIY, 2008). Nesse sentido, o Ártico possuía, nos anos 1980, 172 submarinos operando na região, 2 porta-aviões, 14 embarcações de grande porte, 200 embarcações auxiliares e 400 aeronaves (HEININEN et al, 2014). Analisando esse contexto, a região do Ártico como um todo foi "[...] um dos espaços de maior proximidade e vizinhança entre as superpotências [EUA e URSS]" (COLACRAI, 2004, p. 54, tradução nossa)4. Assim, a zona do Ártico era um dos pontos de contato entre as duas superpotências, sendo uma das regiões mais militarizadas entre elas, pois a possibilidade de ataque via Ártico era extremamente alta. Como bem pontua Colacrai (2004):

Durante toda a Guerra Fria, os Estados que circundam o Ártico [...] estiveram presos nesse discurso geopolítico e estratégico, onde prevaleceram definições muito fechadas referente ao interesse nacional, baseadas no mais bruto realismo. O objetivo era estar permanentemente preparado para repelir a potencial invasão do território por parte do adversário (COLACRAI, 2004, p.55, tradução nossa)5.

\footnotetext{
4 No original: “[...] El espacio de mayor cercania y vecindad entre lãs superpotenciais” (COLACRAI, 2004, p. 54)

5 No original: Durante toda la Guerra Fría, los estados que bordean el ártico - a los que también podemos denominar circumpolares - estuvieron presos de ese discurso geopolítico y estratégico, donde prevalecieron definiciones muy cerradas del interés nacional, basadas em el más crudo realismo. La consigna era estar permanentemente preparado para repeler la potencial invasión del territorio, de uno por del adversario (COLACRAI, 2004, p. 55).
} 
Ainda nesse sentido, é possível utilizar como exemplo a pressão entre a Organização do Tratado do Atlântico Norte (OTAN) e URSS. Após 1945, os EUA reconheceram que um possível ataque ao seu território viria da região polar, sendo necessário estender a participação dos Estados escandinavos e do Oeste Europeu no bloco, tendo a Noruega como um Estado-chave para expandir a influência da OTAN, devido à sua proximidade e território favorável para a expansão do bloco no Ártico (SMITH, 2000). O objetivo desse alargamento era "estrangular" e prevenir o aumento da influência russa, principalmente na região. Em 1949, ocorreram diversos exercícios militares sob o guarda-chuva da OTAN, sendo os países participantes desses exercícios a Groenlândia, o Canadá e os Estados Unidos, buscando colocar em xeque a influência russa na região.

Apesar das tensões da Guerra Fria, a década de 1970, com o arrefecimento da disputa, trouxe um novo entendimento do Ártico para as duas superpotências, não como um espaço para intensa securitização, mas como um espaço para cooperação, sendo, nesse período, assinados acordos para cooperação científica entre EUA e URSS. Em 1984, também foi assinado, entre Canadá e URSS, um acordo para cooperação científica. Ainda, em 1987, com o final da Guerra Fria se aproximando, a mudança de posicionamento foi mais intensa com os discursos de Gorbachev sobre a redução da atividade militar, criando uma zona livre de armamentos (COLACRAI, 2004). Com o colapso da URSS, o Ártico perde, em alguma medida, a sua importância estratégica e econômica para o governo russo, sendo até meados dos anos 1990 considerado um peso para a economia ao invés de uma região com grandes potenciais para o desenvolvimento russo (KONYSHEV; SERGUNIN, 2014). É possível, então, considerar como ponto alto da cooperação no Ártico a criação, em 1996, do Conselho do Ártico, agregando os oito países da região (A-8), que possuem territórios dentro do Círculo Polar Ártico: Canadá, Dinamarca, Estados Unidos, Rússia, Noruega, Finlândia, Islândia e Suécia. Observase, assim, que o Ártico, durante o século XX, passou de um viés conflitivo (especialmente durante a Guerra Fria) para um viés cooperativo (especialmente com a criação do Conselho do Ártico).

\section{OS IMPACTOS AMBIENTAIS NO ÁRTICO}

Durante o século XXI, todavia, a pauta da cooperação científica e comercial no Ártico começou a ter impactos mais significativos devido ao aumento das temperaturas, consequência direta das mudanças climáticas. A temperatura média anual do Ártico, por exemplo, tem aumentado em um ritmo acelerado e maior que a média global, conforme a linha vermelha da Figura 2. 
FIGURA 2 - AUMENTO DAS TEMPERATURAS DO ÁRTICO E GLOBAL DESDE 1900 ATÉ 2020

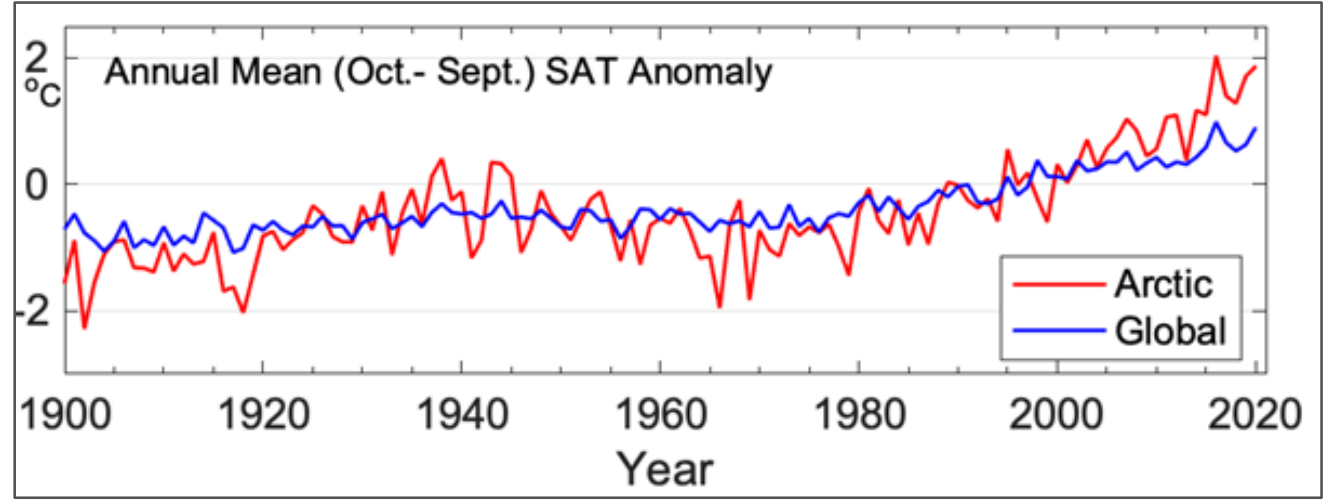

Fonte: Ballinger et al (2020).

Esse aumento nas temperaturas tem causado o degelo tanto na parte terrestre do Ártico quanto na parte marítima. A previsão realizada por cientistas indica que, em meados do século XXI, o cenário da região será consideravelmente diferente em relação à atualidade. Em termos geográficos, o Ártico terá uma transformação no seu terreno, principalmente com a fragilidade do permafrost, que vem surpreendendo pesquisadores por conta de seu derretimento ter ultrapassado as projeções estabelecidas anteriormente, ocorrendo, em alguns casos, o derretimento completo de trechos na Sibéria, revelando um novo terreno por baixo da antiga camada (CRAIG WELCH, 2019). A dissolução das camadas de gelo sobre o mar aumenta anualmente, sendo perceptível, a partir da Figura 3, a oscilação da porcentagem de gelo em março, o mês com maior extensão de gelo, e setembro, o mês com menor extensão de gelo:

FIGURA 3 - OSCILAÇÃO DE GELO NO ÁRTICO DE MARÇO E FEVEREIRO DESDE 1979 ATÉ 2020

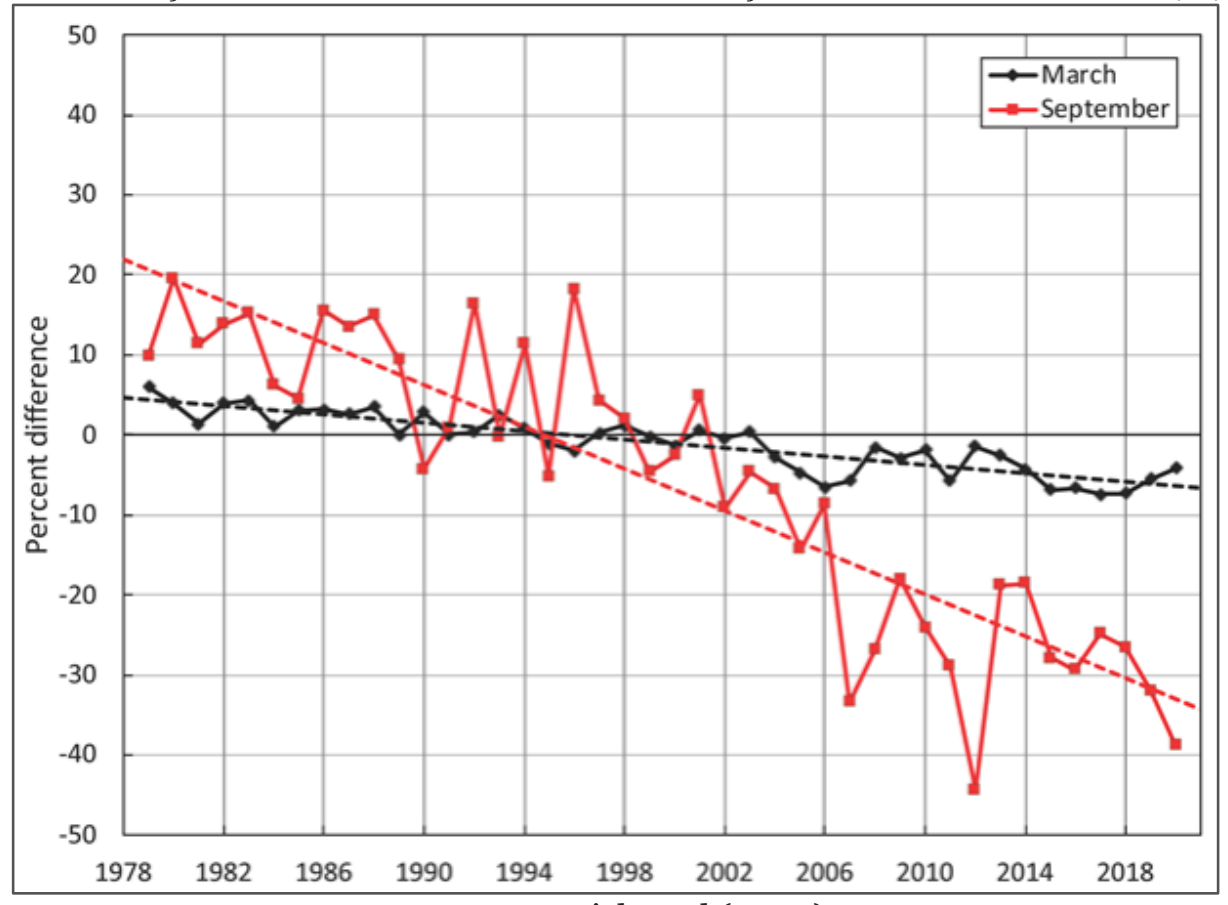

Fonte: Perovich et al (2020). 
A camada de gelo marítimo no Polo Norte, de acordo com o The Arctic Institute (2021), está prevista para desaparecer completamente em verões a partir de 2030. O instituto também projeta o término de quase toda a camada de gelo marítimo no Oceano Ártico a partir de 2100, conforme a Figura 4.

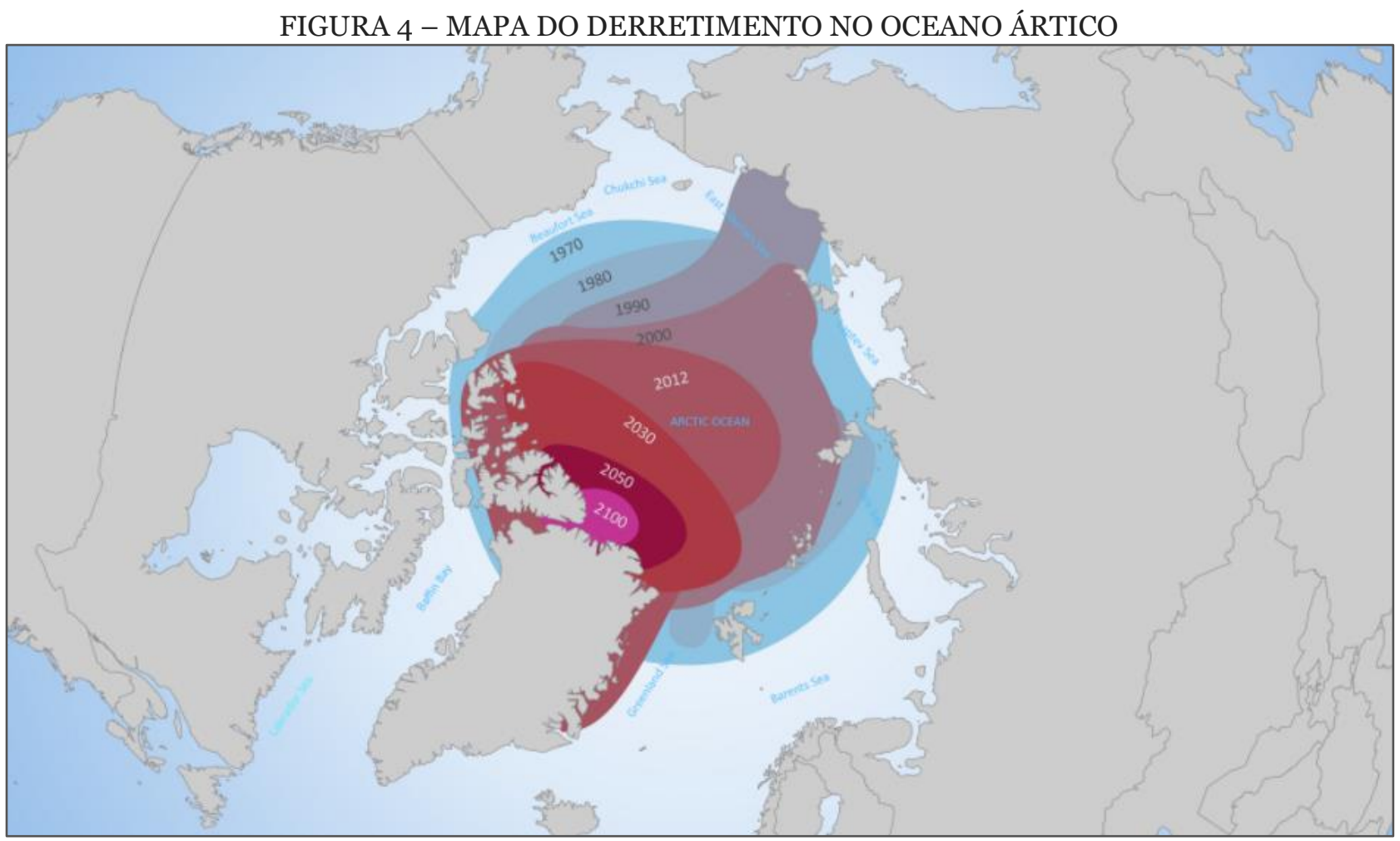

Fonte: The Arctic Institute (2021).

Com o degelo, ocorrerá o aumento do nível do mar que, por consequência, causará o deslocamento de populações que habitam essas costas da região (ZELLEN, 2009). Apesar dessas questões envolvendo o derretimento da região serem um fator de preocupação global:

A Rússia será um dos únicos países desenvolvidos que será beneficiado economicamente pela mudança climática. De fato, sendo um dos países mais nortenhos com uma economia desenvolvida, verá alguns setores como a agricultura e a produção hidroelétrica ganharem por conta da condição climática vantajosa (LAURELLE, 2014, p. 68, tradução nossa) ${ }^{6}$.

O aumento da temperatura está diretamente relacionado à expansão econômica e geopolítica russa, principalmente na Rota do Norte, mencionada anteriormente. Outro ponto de relevância é o acesso a uma nova camada de petróleo e gás natural que eram inacessíveis. Estima-se que $13 \%$ do petróleo mundial e 30\% do gás natural não explorados ainda estão localizados abaixo das camadas

${ }^{6}$ No original: [...] Russia will be the only developed country that stands to benefit economically from climate change. Indeed, being the most northern of countries with a developed economy, it should see some sectors such as agriculture and hydroelectric production gain from more advantageous climatic conditions (LAURELLE, 2014, p. 68). 
de gelo do Ártico, sendo 70\% desse gás natural localizado em território russo (JÚNIOR et al, 2016). Não obstante, o degelo também trará acesso a diversos rios que desaguam no oceano Ártico (SOUZA JÚNIOR et al, 2015).

A melhor navegabilidade no Mar Ártico significa também um acesso cada vez mais rápido à frota russa no Mar Atlântico. Especialmente se relacionarmos a dependência russa aos acessos dos portos nos mares de água quente, notadamente ao Mar Negro, na Crimeia, que possuem grande importância para os interesses russos. Assim, esforços por parte do Estado russo estão cada vez mais ambiciosos para conquistar um controle e domínio efetivo sobre a região ártica. Assim, nesse contexto de mudanças climáticas e afloração de recursos naturais, bem como de interesses russos, é possível perceber a retomada de tensões já vistas durante a Guerra Fria, criando uma nova corrida para o domínio do Ártico, conforme exposto na próxima seção.

\section{O ÁRTICO RUSSO DO SÉCULO XXI}

Na questão geopolítica, a região do Ártico, no governo de Putin, vem tomando atenção equivalente ou até maior que no período soviético. Mediante o crescimento dos efeitos das mudanças climáticas, o objetivo de usar o Ártico, não só como meio de alavancar a sua indústria como também de utilizar seus mares para maior controle e influência regional, torna-se cada vez mais uma realidade tangível para o Estado russo. Diferentemente do período da Guerra Fria, o retorno do Ártico para a agenda militar russa não se dá por motivos securitários dentro de um contexto de confrontação ideológica com o EUA e OTAN, e sim pela proteção de seus interesses geoeconômicos na região, assegurando a sua soberania e demonstrando que a Rússia ainda detém um poder militar relevante no Sistema Internacional. A atuação russa também é uma reação a movimentos de outros Estados do Ártico, como as ações da OTAN através da Noruega e Dinamarca (KONYSHEV; SERGUNIN, 2014).

A descoberta de recursos no Mar Ártico também trouxe disputas referentes à expansão do território marítimo. Nesse sentido, a Convenção das Nações Unidas para a Lei do Mar (UNCLOS, em inglês), de 1984, determina que as Zonas Econômicas Exclusivas (ZEE) não se estendam a mais de 200 milhas náuticas. A UNCLOS prevê também que os Estados que possuem território no Ártico tenham o direito de reivindicar - mediante comprovação de estudos científicos - a necessidade de expandir sua ZEE além das 200 milhas náuticas (GULAS et al, 2017). A Rússia submeteu suas reivindicações para aumentar a sua ZEE, porém se sobrepondo às reivindicações dos outros países do Ártico, conforme mostra a Figura 5. 


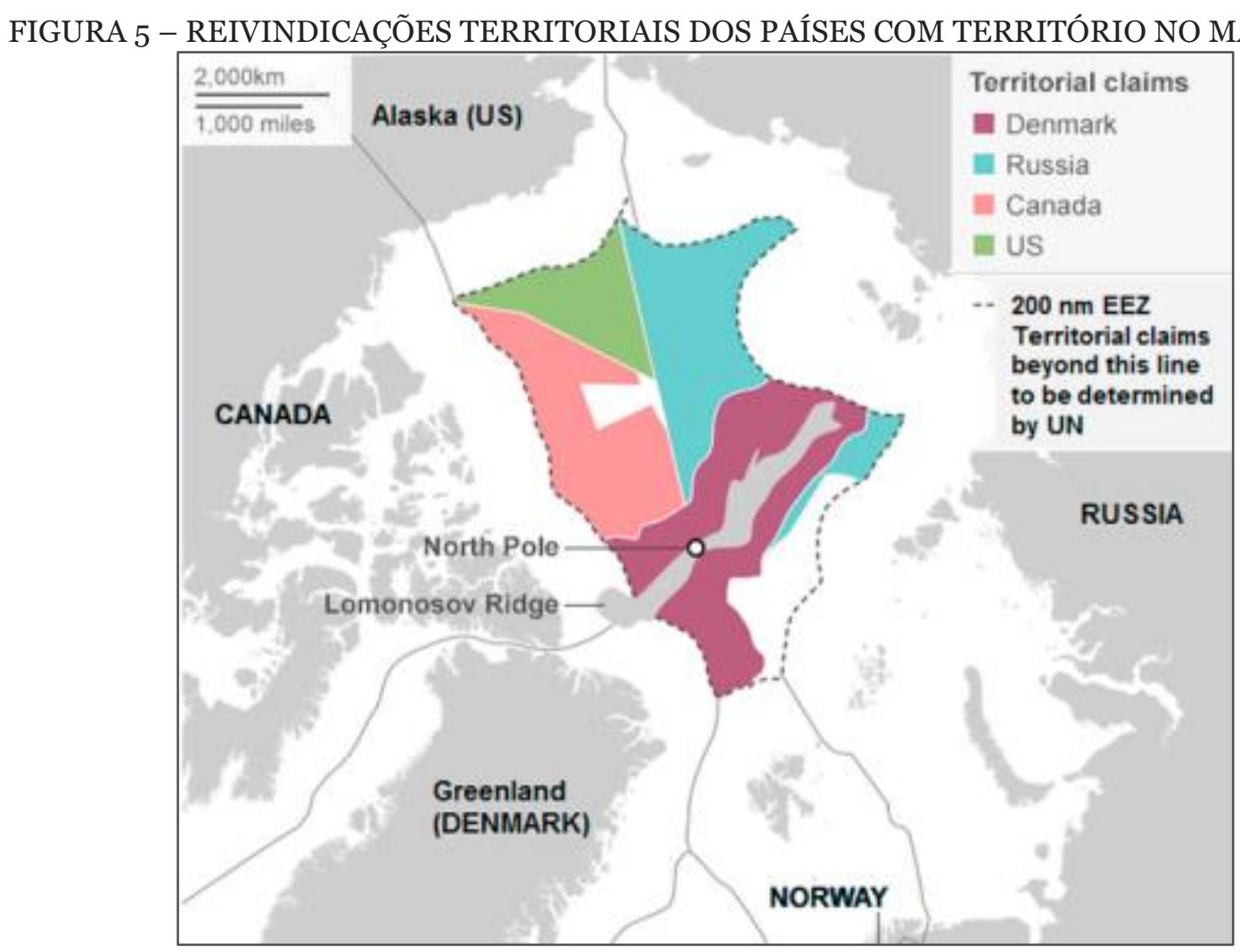

Fonte: Gulas et al (2017).

As reivindicações desses Estados estão alinhadas diretamente com as reservas de hidrocarbonetos que se encontram inexploradas abaixo das camadas de gelo, conforme mostra a Figura 6, com os diversos campos de óleo e gás no Mar de Barents e no Mar de Kara.

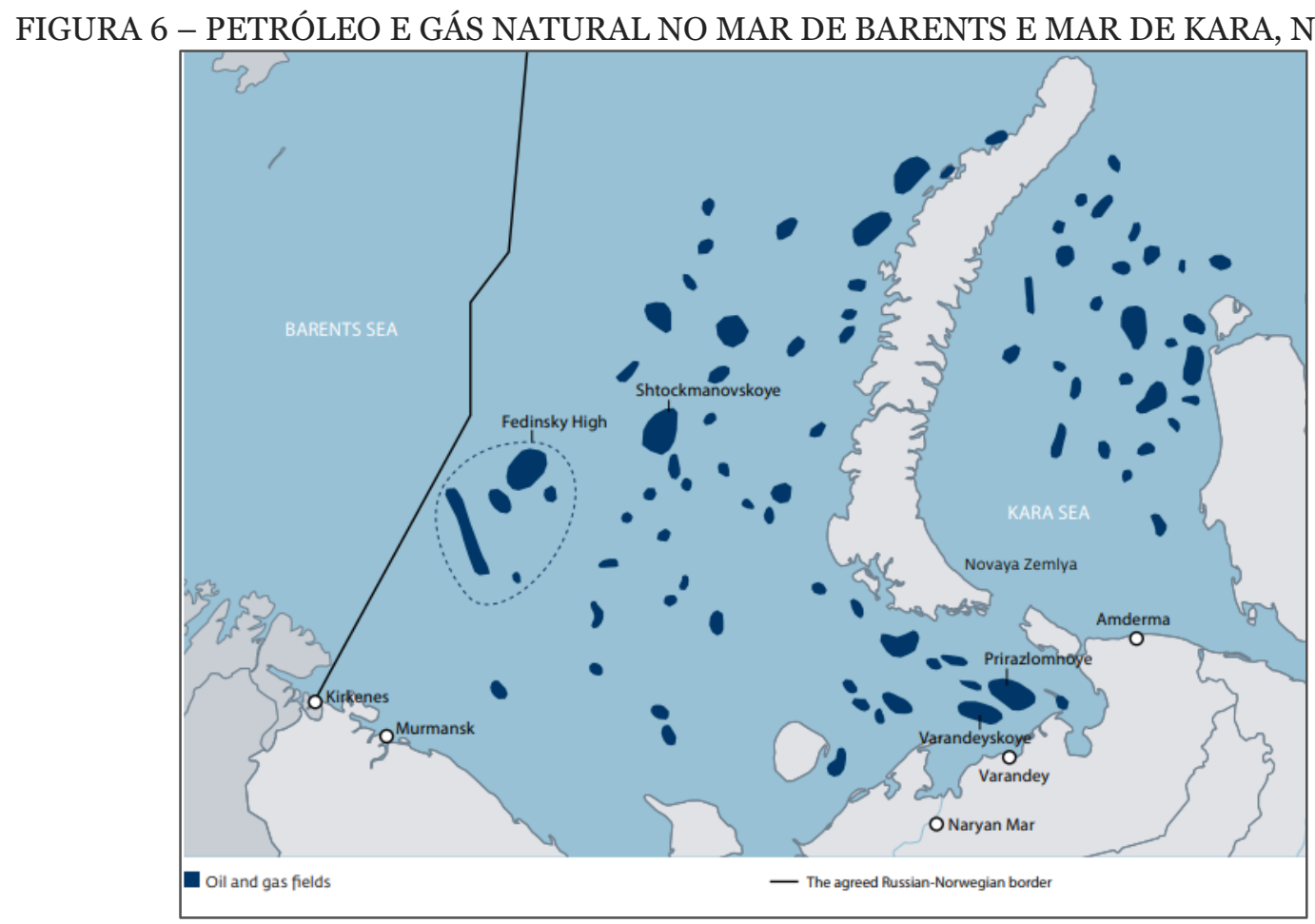

Fonte: Barents Observer (2011). 
Além das reivindicações territoriais, algumas evidências desses crescentes interesses podem ser vistas por meio de ações como a Estratégia para o Ártico, definida pela Federação Russa, em que são descritos aspectos de desenvolvimento socioeconômico, militar, ambiental e de pesquisas e tecnologias (LAURELLE, 2014). Por conta desses interesses, o ambiente de cooperação entre os A-8 foi sendo trocado por uma sensação de disputas geoeconômicas e geopolíticas, tendo como fato que marca essa transição a expedição russa que colocou uma bandeira de titânio no Mar Ártico, em 2007 (SILVA, 2014), advogando para si o território.

Devido às mudanças climáticas que vêm alterando as dinâmicas do jogo geopolítico na região do Ártico, o Estado russo se faz mais presente a um retorno à militarização ocorrido nos períodos mais difíceis da Guerra Fria. Em 2008, foi assinado, pelo presidente Medvedev, o Basic Principles of Russian Federation State Policy in the Arctic to 2020. Esse documento consolida objetivos abrangentes para o Ártico russo, dentre eles, o uso de seus recursos naturais como parte do interesse nacional, reivindicação - em consonância com os acordos internacionais - do território marítimo russo e a cooperação com demais Estados da região, o aumento de órgãos governamentais russos no Ártico e a maior influência militar russa nos mares gelados para garantir a defesa do Estado russo (BERZINA, 2015).

Em 2020, ocorre a assinatura do Basic Principles of Russian Federation State Policy in the Arctic to 2035, atualizando o documento de 2008 e adicionando como princípios de interesse nacional assegurar a soberania e integridade territorial russa na região e desenvolver o Ártico russo como uma área estratégica para o aproveitamento de recursos naturais (KREMLIN, 2020). Como parte da política de maior influência militar no Ártico, o Ministro da Defesa Russo, Vladimir Popovkin, já tinha anunciado o aumento de armamentos avançados, parte do State Arms Procurement Program, em 2011:

A lista de aquisição planejada para o período de 2011-2020 inclui 20 novos submarinos nucleares (dos quais oito são estratégicos), 80 novos navios de superfícies (dos quais 15 são fragatas e 35 corvetas), 600 novos aviões de guerra e mil novos helicópteros [...] O plano de rearmamento proposto excederá qualquer plano de outros Estados do Ártico (ÂTLAND, 2011, p. 268, tradução nossa7).

Assim, ações desta última década vêm demonstrando que a Rússia, mais que qualquer outro país da região, está apta a tomar um controle efetivo do Ártico. Algumas declarações vindas de membros da alta política russa, tomadas nesta última década, evidenciam a formação do controle russo sobre o Ártico. Em 2013, por exemplo, o Presidente Vladmir Putin autorizou a reabertura da base aérea da Ilha Kolteny, localizada mais ao norte do Ártico russo, para a manutenção e segurança de suprimentos da área (PETTERSEN, 2013). Em 2014, o Ministro de Relações Exteriores, Sergey

\footnotetext{
7 No original: "The list of acquisitions planned for the 2011- 2020 period includes 20 new nuclear submarines (of which eight are strategic), 80 new naval surface vessels (of which 15 are frigates and 35 corvettes), 600 new warplanes, and 1,000 new helicopters [...] The proposed rearmament plans greatly exceed the plans of any other Arctic state."
} 
Lavrov, questionou a efetividade e, até mesmo, a presença da OTAN na região do Ártico - há quatro países membros da organização atuando em ampliar suas defesas e presença costeira na região: Canadá, Dinamarca, Estados Unidos e Noruega (ÂTLAND, 2011).

Ainda em conjunto com essa declaração, o Ministro da Defesa, Sergey Shoygu, afirmou estar deslocando tropas para a zona terrestre mais ao norte do Ártico (NIELSEN, 2014). Isso se deve ao fato de que "a deterioração da atual relação pragmática entre a Rússia e a OTAN [...] pode levar a mais aumentos da atividade militar russa na região - em mar, ar e até mesmo em terra” (ÂTLAND, 2011, p. 268, tradução nossa).

Além desses deslocamentos militares para o Ártico, em 2014, foi criado o Joint Strategic Command North que, constituído por forças navais, aéreas e terrestres, visa ser uma entidade permanente no Ártico para desenvolvimento de capacidade das forças armadas russas (SILVA, 2017). Em 2015, Shoygu prestou uma declaração na imprensa em que afirmou um aumento considerável na movimentação militar na região como forma de manter as projeções do interesse nacional russo e a segurança do território do país (PETTERSEN, 2015).

Fica nítida, com os exemplos citados, uma escalada na militarização, tanto do lado russo como do lado ocidental, se usado o Dilema de Segurança (HERZ, 1950). Nesse caso, o aumento de defesas de um Estado causaria uma reação negativa de outros Estados ao seu redor, fazendo com que estes aumentem as suas defesas por conta da sensação de insegurança causada pelo primeiro Estado. Esse aumento de defesas pode ser causado por qualquer tipo de fator, não sendo necessariamente uma resposta a alguma possível agressão. Ainda assim, a percepção de um Estado estrangeiro diante dessa movimentação desperta a insegurança do outro Estado fazendo com que este também invista em sua segurança. Essas ações geram uma reação em cadeia que elevam a tensão da região por conta do alto número de armamentos e instrumentos para a defesa dos Estados (HERZ, 1950).

Com o aumento de armamentos russos em resposta às movimentações securitárias por razões econômicas de outros países e por suas próprias razões já descritas na primeira seção, é perceptível que os Estados ocidentais, em especial membros da OTAN, retomem a estratégia de contenção ocorrida na Guerra Fria. Essa sucessão de eventos e escaladas na segurança da região ficam evidentes nas próprias declarações emitidas pelo governo russo aos avanços militares realizados por países da OTAN e reciprocamente, "sendo que ninguém pode sentir-se completamente seguro em um mundo de unidades competindo entre si” (HERZ, 1950, p. 157, tradução nossa $\left.{ }^{8}\right)$.

Analisando questões marítimas, a Rússia é o único país que possui uma enorme frota de navios quebra-gelo. Esses navios possuem a capacidade de transitar com facilidade pelo congelado Mar Ártico, conseguindo abrir rápido acesso a certas regiões e abrir caminho para outros tipos de

${ }^{8}$ No original: "Since none can ever feel entirely secure in such a world of competing units" (HERZ, 1950, p. 157). 
embarcações, tanto militares como comerciais. A frota atual é composta por 40 exemplares, no qual seis deles são quebra-gelo nucleares (GADY, 2019).

Visto esse cenário, a modernização da frota aliada à criação de novos modelos de QuebraGelo faz parte do programa governamental russo que incluirá 11 novos modelos, nos quais três deles são nucleares. O quebra-gelo mais potente e moderno, chamado de Arktika, é capaz de atravessar tanto mar aberto como águas rasas, podendo quebrar gelo com até três metros de espessura (SILVA, 2017).

Os submarinos também são partes essenciais da estratégia russa no Ártico, sendo usados desde a Guerra Fria por conta de sua capacidade de navegar abaixo das camadas de gelo, não somente no litoral russo como em alto mar. Não só na Guerra Fria como atualmente, grande parte dos submarinos com armamentos nucleares encontram-se na Frota do Norte, situada na Península de Kola. Destacam-se os movimentos russos de equipar os submarinos da classe Delta-IV com mísseis Sineva - capazes de serem lançados abaixo de camadas de gelo e cobrindo uma distância de 8,3 mil km - e os submarinos da classe Typhoon com mísseis de cruzeiro de longa distância (SERGUNIN; KONYSHEV, 2017). Ambos os submarinos classe Delta-IV e Typhoon serão gradualmente substituídos no futuro pela quarta geração de submarinos classe Borey, com capacidade de camuflagem superior às duas classes e gerações anteriores (RÚSSIA, 2017a).

Segundo Atland (2011), a vantagem dessa região é a ausência de gelo nos arredores dos portos, facilitando a movimentação e camuflagem de submarinos, podendo estes, a partir de uma zona sem gelo, submergir e prosseguir mar adentro abaixo de camadas de gelo, podendo até emergir nas próprias zonas congeladas para disparar algum míssil (ÂTLAND, 2011). Todavia derretimentos nas camadas de gelo marítimo vêm alterando a estratégia dos submarinos russos pois, sem as camadas de gelo, estes ficam mais expostos à detecção (SERGUNIN; KONYSHEV, 2017). Nesse sentido, a modernização das frotas de submarinos e a gradual substituição dos Delta-IV e Typhoon pela classe Borey apresentam novas maneiras de lidar com as mudanças que ocorrem no Ártico.

Ainda na questão marítima, o comandante da Frota do Norte realizou, em 2017, uma declaração sobre os exercícios militares terem dobrado em relação ao ano anterior, principalmente com exercícios relacionados a submarinos e sobre embarcações militares (RÚSSIA, 2017b). Em 2017, a Frota do Norte realizou mais de 4,7 mil exercícios militares na região (BOULÈGUE, 2019).

Referente aos testes militares, foi realizado, em 2019, exercícios militares envolvendo o navio antissubmarino Severomorsk e o sistema Kinzhhal de defesa aérea. Esses exercícios contribuíram para a atenuação das tensões entre os países nórdicos, devido a sua execução dentro do Mar Norueguês (RÚSSIA, 2019). Ainda, a Rússia lançou na república de Comi e na região de Murmansk, dois novos radares antimísseis para serem incluídos ao Sistema de Alerta de Ataque de Mísseis que compõe a defesa aeroespacial russa, e ainda há a previsão de, nos próximos anos, serem lançados mais dez complexos de vigilância por rádio e laser (SPUTNIK BRASIL, 2019). 
Ainda em 2019, a Rússia lançou o seu projeto para a expansão e desenvolvimento no Ártico. A usina nuclear flutuante consiste em um navio/reator nuclear que abastecerá petroleiros e zonas remotas perto da costa de Chuktka, próxima ao Alaska (ROSATOM, 2020). Além dessas atividades descritas acima, ainda em 2015, a revista Bussines Insider realizou um levantamento de todas as bases russas operantes no Ártico, no qual percebem-se 18 bases, sendo muitas delas próximas aos campos de óleo e gás ou instaladas em pontos de estrangulamento que favorecem o controle das rotas, conforme a Figura 7:

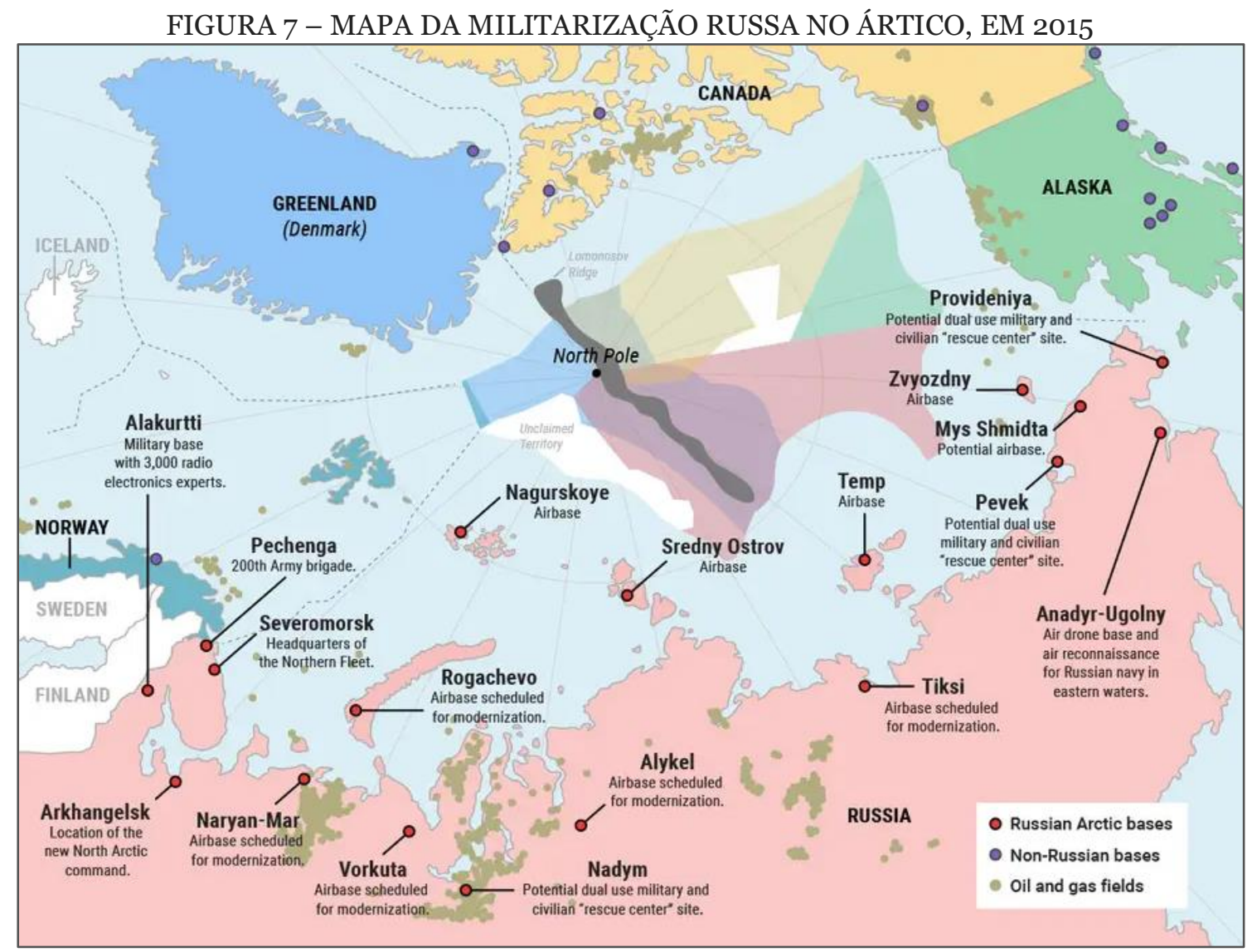

Fonte: Business Insider (2015).

Todas essas ações demonstram um projeto de Estado direcionado para a expansão do Ártico como região pertencente à Rússia, levando em consideração uma geopolítica dedicada à exploração de hidrocarbonetos que se encontram na região, bem como a maior influência na rota do Mar do Norte. É possível ainda, utilizar-se da Balança de Poder (WALTZ, 1979; WALT, 1985) para entender os movimentos em conjuntos de outros Estados da região a respeito da Rússia.

A Balança de Poder ou Balancing ocorre quando um Estado se sente ameaçado por outro. Esse sentimento de ameaça por parte de um Estado pode ser causado por conta do poder agregado - capacidade tecnológica, militar e industrial -, a proximidade, a capacidade e as intenções ofensivas. O Estado que se sente ameaçado busca reforço em sua segurança mediante alianças com 
outros Estados para fazer contrapeso ao Estado que está desestabilizando a região ou o próprio Estado menor (WALT, 1985).

Partindo desse aspecto teórico, é possível aplicá-lo na região do Ártico levando em consideração a Rússia como o Estado que causa o desequilíbrio de poder, devido ao desenvolvimento militar na região já mencionado anteriormente. Pode-se entender então que ela exerce, dentro do contexto do Balancing, três papéis: i) o de Estado com muito poder agregado, devido a todo o seu território e capacidade militar imposta na região; ii) o de Estado próximo, devido a sua localização próxima aos Estados nórdicos e aos EUA; e iii) o de Estado com capacidade ofensiva devido aos diversos testes e atividades militares que vem ocorrendo no Ártico. Destaca-se, como já mencionado anteriormente neste artigo, que a Rússia não apresenta um interesse em disputas como as existentes no período da Guerra Fria. Logo entende-se que afirmar sua soberania no Ártico é interpretada como parte da capacidade ofensiva russa. Com esses papéis, Estados ocidentais realizam uma "aliança" para contrabalancear o poder russo no Ártico. Entende-se que a aliança em questão pode muito bem ser o uso da OTAN na região como também os diversos exercícios em conjunto realizados pelos Estados nórdicos.

\section{O IMPACTO DAS AÇÕES RUSSAS NO ÁRTICO EM OUTROS ESTADOS}

Levando em consideração o Balancing exemplificado anteriormente, o "sistema de aliados" contrário à movimentação russa consiste em alguns Estados nórdicos que vêm realizando uma movimentação militar no sentido tanto de fazer uso dos recursos naturais como também de conter o avanço russo. Fora da região, também há Estados que observam nos mares gelados a oportunidade de expandir suas rotas comerciais e tirar algum proveito econômico do Ártico, como é o exemplo da China (SILVA, 2017).

No espectro individual dos países nórdicos, a Noruega destaca-se como o Estado que mais tem investido na militarização do Ártico, contando em seu exército com cinco fragatas e seis embarcações de patrulha. Aliada a essa modernização, a Noruega é um dos Estados responsáveis pela organização de exercícios militares que ocorrem na região a cada dois anos chamado de Cold Response. Esse exercício conta com a presença de países da região, incluindo a própria Rússia (SILVA, 2017). Além desse exercício, a cooperação entre Noruega e Rússia tem tido boas intenções por parte do Estado norueguês, porém não apresentam novas diretrizes em conjunto, sendo as violações internacionais da Rússia na Ucrânia um ponto que também traz ceticismo para a cooperação (NORUEGA, 2017). Ainda assim, a Noruega é um país membro da OTAN e, tendo em vista os avanços militares que a Rússia faz na região, sua estratégia oficial para o Ártico é moldada por conta delas, sendo explicitada no trecho de seu documento oficial para estratégia no Ártico: 
Nos últimos dez anos, a atividade militar russa no Norte aumentou. Esse aumento na atividade não é considerado direcionado para a Noruega, mas ainda assim é um importante fato na política de defesa e segurança na Noruega (NORUEGA, 2017, p. 18, tradução nossa9).

As Forças Armadas seguem uma diretriz de manutenção de defesa da soberania norueguesa, sendo muito enfatizada pela operação com forças aliadas (NORUEGA, 2017). É possível entender que os esforços militares russos, até $2017^{10}$, não estavam causando muitas mudanças além dessas já mencionadas, sendo questão de tempo até que as políticas de segurança e defesa sejam renovadas com um caráter mais rígido para a região.

Outro país de destaque na região é a Dinamarca e sua extensão territorial de valor estratégico, a Groelândia. A Dinamarca, assim como a Noruega, também é um Estado membro da OTAN. Deixando de lado os documentos do bloco ocidental, documentos oficiais direcionados para estratégias no Ártico apresentam o posicionamento voltado para a cooperação entre os Estados do Círculo Polar e a defesa de meio ambiente por conta dos impactos das mudanças climáticas. Ainda assim, há trechos que evidenciam uma pequena preocupação direcionada à defesa da soberania:

Ainda que a o relacionamento de trabalho com os Estados costeiros do Oceano Ártico seja próximo, haverá a necessidade de reforçar a soberania do Reino, especialmente tendo em vista a antecipação do aumento de atividade na região (DINAMARCA, 2011, p. 20, tradução nossa $\left.{ }^{11}\right)$.

Nesse sentindo, é possível entender que mesmo os países com uma agenda focada na cooperação científica e ambiental no Ártico apresentam preocupações referentes à atuação russa, podendo levar a um investimento militar no Ártico perante um possível cenário futuro de tensões.

Já os Estados Unidos são um dos principais países a fazer contraparte às ações russas na região, sendo ele parte do A-5, aqueles Estados que possuem litoral voltado para o interior do oceano Ártico, através de seu território do Alaska. Como já mencionado nas seções anteriores, o território estadunidense que faz ligação com o território russo foi uma das zonas mais militarizadas do planeta durante a Guerra Fria. Apesar disso, atualmente, os Estados Unidos possuem poucos planos econômicos para o seu território na região e também bases na região, que diminuíram significativamente após o término da Guerra Fria, como cita Borgerson (2008):

Apesar do potencial de derretimento da camada de gelo para transformar a navegação global e os mercados de energia, questões do Ártico são, em sua maioria,

\footnotetext{
${ }^{9}$ No original: Over the last ten years, Russian military activity in the north has increased. This increase in activity is not considered to be targeted at Norway, but it is nevertheless an important factor in Norway's security and defense policy (NORUEGA, 2017, p. 18)

${ }^{10}$ Até o momento, 2021, as estratégias para o Ártico não foram renovadas, sendo o documento de 2017 vigente em relação às políticas correntes do Estado norueguês.

${ }^{11}$ No original: Even though the working relationship of the Arctic Ocean's coastal states is close, there will be a continuing need to enforce the Kingdom's sovereignty, especially in light of the anticipated increase in activity in the region (DINAMARCA, 2011, p. 20).
} 
ignoradas pelo alto escalão no U.S. State Department e no U.S. National Security Council (BORGERSON, 2008, p. 71, tradução nossa' ${ }^{12}$ ).

Ainda que ao longo da última década o Ártico vem tornando-se novamente um ponto de atenção para o EUA, este não consegue competir individualmente com a infraestrutura russa na região, tendo ficado para trás na corrida que se desenvolve entre as potências do Ártico (BORGERSON, 2008). Muito disso deve-se à falta de instalações portuárias em águas profundas, aeródromos e capacidade de navegação na área. O principal mecanismo que os EUA possuem para refrear as atividades russas é a OTAN, em que consegue dispor de uma lógica da Guerra Fria para tentar manter a contenção contra a Rússia.

Um dos maiores pontos de tensão entre a Rússia e a OTAN no Ártico encontra-se em torno do que Atland (2011) chama de "zonas de estrangulamento", localizadas em torno do ponto de encontro entre a Groelândia, Islândia e Reino Unido e também no Mar Norueguês. Em ambos esses pontos, as forças armadas estadunidenses possuem diversos sistemas submarinos de vigilância como o Sound Surveillance System (SOSUS) para detectar qualquer movimento russo na região, prática recorrente já na Guerra Fria. Nesse sentido, podemos ver fora do lado estadunidense, porém ainda na OTAN, um rearmamento crescente de países como Canadá, Dinamarca e Noruega, principalmente no âmbito marítimo, levando a uma deterioração do relacionamento entre a Rússia e a OTAN (ATLAND, 2011). Pode-se atribuir ainda o Dilema da Segurança de Herz (1950), abordado anteriormente, para classificar o aumento da tensão não só entre os países como também com o bloco ocidental, se levarmos esse último como um ator único que age e reage com o aumento de sua defesa e segurança na região. Nesse sentido, a política externa russa para a região é altamente influenciada e trabalha em resposta aos atos de sua contrapartida no Ártico, a OTAN, que por sua vez trabalha suas ações em resposta aos atos da Rússia na região.

A China também teve um crescimento evidente de sua influência no Ártico. Essa influência leva em consideração os interesses chineses na possibilidade comercial que as rotas comerciais do Ártico oferecem em comparação com sua rota usual de comércio que envolve o Canal de Suez. Além das rotas, a economia chinesa necessita cada vez mais de recursos energéticos para manter seu desenvolvimento, sendo parte de seu interesse a exploração dos recursos do Ártico. O olhar da China não só é direcionado para a Rússia como também aos demais países que compõem o Conselho do Ártico, a fim de desenvolver uma governança conjunta na região para aproveitar os recursos e oportunidades da área (CHINA, 2018).

Por meio de investimentos nesses países, o Estado chinês ganha mais espaço para progredir com sua agenda regional. Desse modo, a Rússia exerce um papel de guardião do Ártico para os países asiáticos que desenvolvem agendas para a região, em especial a China. Assim, esforços diplomáticos

\footnotetext{
${ }^{12}$ No original: Despite the melting icecap's potential to transform global shipping and energy markets, Arctic issues are largely ignored at senior levels in the U.S. State Department and the U.S. National Security Council (BORGERSON, 2008, p. 71).
} 
são exercidos pela parte chinesa com outros atores do Ártico, incluindo a Rússia, por conta de todo o seu papel na região. Os interesses chineses e, em especial com a Rússia, estão focados principalmente na cooperação estratégica do setor de energia e pesquisas climáticas, sendo uma agenda que não interfere com o interesse nacional russo (RØSETH, 2014). Não obstante, as relações no Ártico são voláteis e podem, à medida que os recursos energéticos ficam acessíveis e há mais militarização na área, mudar o direcionamento da relação sino-russa.

Observando as ações da Noruega, Dinamarca, China e o bloco da OTAN, entende-se que os países ocidentais possuem uma agenda política para a região mais dissuasiva que os países asiáticos - como a China - sendo estes mais focados em desenvolver uma parceria estratégica com a Rússia no setor energético e científico. O lado ocidental percebe o aumento da militarização russa no Ártico como uma tentativa de assegurar, cada vez mais, suas zonas estratégicas e ampliar sua influência para fora de seus territórios. Por conta disso, Noruega e Dinamarca apresentam em suas políticas o papel das forças armadas para a manutenção da soberania na região, tendo em vista uma futura escalada nas tensões entre o Ocidente e a Rússia. Aliada ao mesmo sentimento, a OTAN busca com seus membros reforçar a contenção à expansão russa por meio de exercícios e equipamentos militares na região.

\section{CONSIDERAÇÕES FINAIS}

O Ártico possui fundamental relevância em níveis geopolíticos para o sistema internacional. A região foi palco importante das dinâmicas da Guerra Fria e, apesar, do Conselho do Ártico atuar como um promotor da cooperação entre os Estados árticos, as ações russas e da OTAN mostram um acirramento de interesses divergentes na região. Assim, o artigo objetivou discutir como o degelo do Ártico, advindo das intensas mudanças climáticas, vem influenciando as dinâmicas geopolíticas do Estado russo na região, demonstrando uma correlação direta entre a exposição dos recursos energéticos e o aumento da militarização, tanto pelos russos como pelos demais Estados árticos, podendo escalar para um nível de tensão igual ou maior que o da Guerra Fria.

Por meio das políticas direcionadas para o Ártico, especialmente no governo Putin, a Rússia tem realizado investimentos visando assegurar a soberania, como a execução de exercícios militares, renovação da frota de quebras-gelo e submarinos e restauração de ex-bases soviéticas em seus territórios na região. Pode-se observar essas ações tanto no sentido de conter o estrangulamento feito pela OTAN - não só no Ártico, mas no Leste Europeu e, em especial, na Criméia - como para projetar sua influência nas zonas estratégicas, ricas em petróleo, gás natural e navegabilidade.

O propósito russo é, portanto, garantir que o Ártico seja a sua nova frente geopolítica, uma vez que o acesso russo aos oceanos é vulnerável. Com o degelo, os portos árticos, que ficam em águas congeladas na maior parte do ano, poderiam ser utilizados ilimitadamente, fazendo com que a Rússia 
deixe de depender de outros acessos que podem facilmente ser bloqueados. Além disso, os recursos naturais presentes na região podem ser decisivos nos propósitos russos de modernização econômica, militar e geopolítica.

A partir dos pressupostos teóricos do Dilema da Segurança (HERZ, 1950) e o Balancing (WALTZ, 1979; WALT, 1985), observa-se o aumento de investimento também do lado ocidental na região, bem como a criação de um sistema de cooperação em defesa da soberania dos Estados no Ártico, todos explicitados em documentos oficiais direcionado às políticas na região. Nesse sentido, o desgaste das relações entre Rússia e os outros atores - em destaque para a OTAN - demonstra que fica cada vez mais evidente o surgimento de um cenário de tensão caminhando com as mudanças climáticas.

Então, na medida em que as mudanças climáticas ocasionam o degelo e revelam novas camadas de recursos energéticos, o impacto territorial nas dinâmicas securitárias por conta da mudança física das regiões e a permanência na atividade de rotas comerciais no Mar Ártico ficam mais evidentes. Assim, em alguns anos, o Ártico poderá se tornar um palco de disputas econômicas e securitárias. Ainda assim, destaca-se que as disputas não terão o caráter ideológico, entre outros fatores presentes na Guerra Fria, e que a presença de novos atores na região, como a China e outros países com interesses na abertura de novas rotas marítimas e recursos situados no Ártico, podem tornar ainda mais complexas as dinâmicas regionais.

*Artigo recebido em 29 de agosto de 2020, aprovado em 01 de março de 2021.

\section{REFERÊNCIAS}

ÅTLAND, Kristian. Russia's Armed Forces and the Arctic: All Quiet on the Northern Front? Contemporary Security Policy, [s.l.], v. 32, n. 2, p.267-285, ago. 2011. Informa UK Limited. Disponível em: <http://dx.doi.org/10.1080/13523260.2011.590354>. Acesso em 07 mar. 2021.

BALLINGER, T.J. et al. NOAA Arctic Report Card 2020: surface air temperature. Washington: National Oceanic and Atmospheric Administration, 2020. 7 p. Disponível em: <https://doi.org/10.25923/gcw8-2z06 > . Acesso em: 22 jan. 2021.

BARENTS OBSERVER. Zarubezhneft wants Fedinsky High. 2011. Disponível em: <https://barentsobserver.com/en/articles/zarubezhneft-wants-fedinsky-high >. Acesso em: 03 fev. 2021.

BERZINA, Ieva. Foreign \& Domestic Discourse on the Russian Arctic. In: HEININEN, Lassi; EXNER-PIROT, Heather; PLOUFFE, Joël. Arctic Yearbook 2015. Akureyri: Northern Research Forum, 2015. 28 p. 281-295. Disponível em: <https://findresearcher.sdu.dk:8443/ws/portalfiles/portal/129580259/Arctic Yearbook 2015.pd

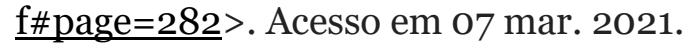


BOULÈGUE, Mathieu. Russia's Military Posture in the Arctic: managing hard power in a low tension environment. Londres: Chatham House, 2019. Disponível em: https: $<$ um.fi/documents/35732/o/Chatham+House+Russias+Military+posture+in+the+Arctic Managing+Hard+Power+in+a+Low+Tension+Environment.pdf/ge353596-2c1d-bc59-f66a5487937268be?t=1568107600468 > . Acesso em: 11 fev. 2021.

BUSINESS INSIDER. Business Insider. This map shows Russia's dominant militarization of the Arctic. 2015. Disponível em: <https://www.businessinsider.com/chart-of-russiasmilitarization-of-arctic-2015-8>. Acesso em 07 mar. 2021.

CHINA. Ministry of Foreign Afairs of the Peoples Republic of China. China's Arctic Policy. 2018. Disponível em: <https://www.fmprc.gov.cn/mfa eng/wjdt 665385/wjzcs/t1529332.shtml > . Acesso em: 17 fev. 2021.

COLACRAI, Miryam. El Ártico y la Antártida en las relaciones internacionales. Porto Alegre. Editora da UFRGS, 2004.

CRAIG WELCH. National Geographic. Arctic permafrost is thawing fast. That affects us all. 2019. Disponível em: <https://www.nationalgeographic.com/environment/2019/o8/arcticpermafrost-is-thawing-it-could-speed-up-climate-change-feature/>. Acesso em 07 mar. 2021.

DINAMARCA. Ministry of Foreign Affairs of Denmark. Kingdom of Denmark Strategy for the Arctic 2011-2020. Copenhagen, 2011.

DUGIN, Alexander. Last War of the World-Island: the geopolitics of contemporary Russia. Londres: Arktos, 2015.

GADY, Franz-Stefan. Russia Launches New Nuclear-Powered Icebreaker. The Diplomat. 2019. 27 mai. 2019. Disponível em: <https://thediplomat.com/2019/05/russia-launches-new-nuclearpowered-icebreaker/>. Acesso em 07 mar. 2021.

GULAS, Sarah; DOWNTON, Mitchell; D'SOUZA, Kareina; HAYDEN, Kelsey; WALKER, Tony R.. Declining Arctic Ocean oil and gas developments: opportunities to improve governance and environmental pollution control. Marine Policy, [S.L.], v. 75, p. 53-61, jan. 2017. Disponível em: <http://dx.doi.org/10.1016/j.marpol.2016.10.014>. Acesso em: 10 fev. 2021.

GUNITSKIY, Vsevolod. On Thin Ice: Water Rights and Resources Disputes in the Arctic Ocean. Journal Of International Affairs, New York, v. 61, n. 2, p. 261-271, jun. 2008. Disponível em: <https://www.researchgate.net/profile/Seva Gunitsky/publication/228149239 On Thin Ice W ater Rights and Resource Disputes in the Arctic Ocean/links/55a015d508ae032efo545384/ On-Thin-Ice-Water-Rights-and-Resource-Disputes-in-the-Arctic-Ocean.pdf $>$. Acesso em: 09 fev. 2021.

HEININEN, Lassi; SERGUNIN, Alexander; YAROVOY, Gleb. Russian Strategies in the Arctic: Avoiding a New Cold War. Moscou: Valdai, 2014. Disponível em: <https://valdaiclub.com/files/11482/>. Acesso em: 10 fev. 2021.

HERZ, John H. Idealist Internationalism and the Security Dilemma. World Politics, [s.l.], v. 2, n. 2, p.157-180, jan. 1950. Cambridge University Press (CUP). Disponível em

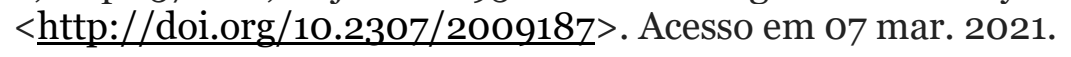

JOSEPHSON, Paul R. The Conquest of the Russian Arctic. Cambridge, Massachusetts e Londres: Harvard University Press, 2014. 
KONYSHEV, Valery; SERGUNIN, Alexander. Is Russia a revisionist military power in the Arctic? Defense \& Security Analysis, [S.L.], v. 30, n. 4, p. 323-335, set. 2014. Disponível em:

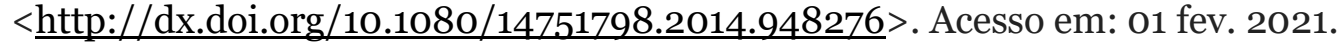

NIELSEN, Thomas. Russia says no need for NATO in Arctic, expands own military presence. Barents Observer. 22 out. 2014. Disponível em: <https://barentsobserver.com/en/security/2014/10/russia-says-no-need-nato-arctic-expandsown-military-presence-22-10 > . Acesso em 07 mar. 2021.

NORUEGA. Norwegian Ministry of Foreign Affairs. Norway's Arctic Strategy - between geopolitics and social development. Oslo, 2017. Disponível em: <https://www.regjeringen.no/contentassets/fad46fo404e14b2agb551ca7359c1000/arcticstrategy.pdf $>$ Acesso em 07 mar. 2021.

PEROVICH, Donald et al. Arctic Report Card 2020: sea ice. Washington: National Oceanic And Atmospheric Administration, 2020. 10 p. Disponível em: <https://doi.org/10.25923/n170-9h57>. Acesso em: 22 jan. 2021.

PETTERSEN, Trude. Russia re-opens Arctic cold war era air base. Barents Observer. 30 out. 2013. Disponível em: <https://barentsobserver.com/en/security/2013/10/russia-re-opens-arctic-coldwar-era-air-base-30-10>. Acesso em 07 mar. 2021.

PETTERSEN, Trude. Shoygu: Military presence in the Arctic is a question of national security. Barents Observer. 29 fev. 2015. Disponível em: $<$ https://barentsobserver.com/en/security/2015/02/shoygu-military-presence-arctic-questionnational-security-26-02>. Acesso em 07 mar. 2021.

ROSATOM. ROSATOM: world's only floating nuclear power plant enters full commercial exploitation. 2020. Disponível em: <https://rosatom.ru/en/presscentre/news/rosatom-world-s-only-floating-nuclear-power-plant-enters-full-commercialexploitation/?sphrase id=1767346>. Acesso em: 05 fev. 2021.

RØSETH, Tom. Russia's China Policy in the Arctic. Strategic Analysis, [s.l.], v. 38, n. 6, p. 841859, 2 nov. 2014. Informa UK Limited. <http://dx.doi.org/10.1080/09700161.2014.952942>. Acesso em 07 mar. 2021.

RÚSSIA. Ministry of Defense of the Russian Federation. First Project Borey-A nuclear underwater missile carrier to be floated out in Severodvinsk, November 17. 2017a. Disponível em: <http://eng.mil.ru/en/news page/country/more.htm?id=12151020@egNews >. Acesso em: 03 fev. 2021.

RÚSSIA. Ministry of Defense of The Russian Federation. Northern Fleet ASW Severomorsk completes test shooting Norwegian sea. 2019. Disponível em: $<$ http://eng.mil.ru/en/news page/country/more.htm?id=12231536@egNews $>$. Acesso em 07 mar. 2021.

RÚSSIA. Ministry of Defense of The Russian Federation. The Foreign Policy Concept of the Russian Federation. 31 mai. 2017b. Disponível em: $<$ http://eng.mil.ru/en/news page/country/more.htm?id=12126528@egNews $>$. Acesso em 07 mar. 2021.

RÚSSIA. President of Russia. Vladimir Putin approved basic principles of state policy in the Arctic. 2020. Disponível em: <http://en.kremlin.ru/acts/news/62947>. Acesso em: 17 fev. 2021. 
SERGUNIN, Alexander; KONYSHEV, Valery. Russian military strategies in the Arctic: change or continuity?. European Security, [S.L.], v. 26, n. 2, p. 171-189, 3 abr. 2017. Disponível em: <http://dx.doi.org/10.1080/09662839.2017.1318849>. Acesso em: 03 fev. 2021.

SILVA, Alexandre Pereira da. A China Também Olha para o Ártico. Austral: Revista Brasileira de Estratégia \& Relações Internacionais, Porto Alegre, v. 3, n. 6, p.95-117, dez. 2014. Disponível em: $<$ https://www.seer.ufrgs.br/austral/article/viewFile/49873/33168>. Acesso em 07 mar. 2021.

SILVA, Carolina Sofia Nóbrega da. A Geopolítica do Ártico e a política externa da Rússia para a região (2007-2017). 2017. 84 f. Tese (Doutorado) - Curso de Relações Internacionais, Instituto Superior de Ciências Sociais e Políticas, Universidade de Lisboa, Lisboa, 2017.

SMITH, Mark. NATO Enlargement during the Cold War: Strategy and System in the Western Alliance. Nova York: Palgrave, 2000.

SOUZA JÚNIOR, Enoil de; ROSA, Kátia Kellem da; SIMÕES, Jefferson Cardia. Geopolítica do Ártico: mudanças nas políticas para o norte. Geographia Meridionalis, Pelotas, v. 1, n. 2, p. 248267, jul. 2015 .

SPUTNIK BRASIL (Brasil). Rússia vai implantar 2 novos radares antimísseis no Ártico. 2019. Disponível em: <https://br.sputniknews.com/defesa/2019100414598032-russiavai-implantar-2-novos-radares-antimissil-no-artico/>. Acesso em: 21 out. 2019.

THE ARCTIC INSTITUTE. Beyond the Melt. 2021. Disponível em: <https://www.thearcticinstitute.org/projects/climate-change >. Acesso em: 25 jan. 2021.

THOMAN, Richard L.; RICHTER-MENGE, Jacqueline; DRUCKENMILLER, Matthew L.. NOAA Arctic Report Card 2020. Arctic Report Card 2020, Washington, p. 1-141, dez. 2020. Disponível em:

$<$ https://arctic.noaa.gov/Portals/7/ArcticReportCard/Documents/ArcticReportCard full report2 020.pdf $>$. Acesso em: 01 fev. 2021.

WALT, Stephen M. Alliance Formation and the Balance of World Power. International Security, [s.l.], v. 9, n. 4, p.3-43, 1985. JSTOR. Disponível em: <http://dx.doi.org/10.2307/2538540 >. Acesso em 07 mar. 2021.

WALTZ, Kenneth N. Anarchic Orders and Balances of Power. In: WALTZ, Kenneth N. Theory of International Politics. California: Addison-wesley Publishing Company, 1979. p. 103-128.

ZELLEN, Barry Scott. Arctic Doom, Arctic Boom: The Geopolitics of Climate Change in the Arctic. Santa Barbara: Abc-clio, 2009. 